\title{
Ordenamiento Territorial Como Propuesta De Desarrollo Económico Local Estudio De Caso: Propuesta De Plan De Desarrollo Y De Ordenamiento Territorial Para El Cantón Alausí, Componente Económico Productivo
}

\author{
Catalina Margarita Verdugo Bernal \\ Docente - Investigador de la Facultad de Recursos Naturales \\ Escuela Superior Politécnica De Chimborazo - Ecuador \\ Ángela Paulina Rivera Riera \\ Maestrante, Instituto de Educación Continua y Posgrado \\ Escuela Superior Politécnica De Chimborazo - Ecuador \\ Otto Fernando Balseca Sampedro \\ Edwin Fernando Viteri Nuñez \\ Docente - Investigador de la Facultad de Mecánica \\ Escuela Superior Politécnica De Chimborazo - Ecuador \\ Jaime Robert Guevara Layedra \\ Consultor independiente. ECUADOR.

\section{Paulina Beatriz Díaz Moyota \\ Juan Hugo Rodríguez Guerra} \\ Docente - Investigador de la Facultad de Recursos Naturales \\ Escuela Superior Politécnica De Chimborazo - Ecuador
}

doi: 10.19044/esj.2016.v12n28p482 URL:http://dx.doi.org/10.19044/esj.2016.v12n28p482

\begin{abstract}
An economic development and land use planning proposal for Alausí County, Chimborazo was created as part of this research. The research started with an analysis of the current situation in the productive area of the county. With the help of participative workshops, it was possible to identify principal problems and opportunities; these topics helped in the definition of development strategies. Alausí is a rural area with $76 \%$ employment. Most are engaged in farming activities on sandy loam soils with slopes ranging from 15 to 45 degrees. Despite the ruggedness, 39\% of the area is appropriate for farming activities, in which the principal products are barley, corn, potato, and fresh milk. Access to technology is a principal barrier to economic growth and profitability in production. It is
\end{abstract}


recommended that the municipality of Alausí implement various projects identified by this research in order to capitalize on the productive area of the county and to improve quality of life.

Keywords: Development Proposal, Rural Development, Development Strategies, Development Programs, Sustainability, Economic And Productive Component, Alausi County, Chimborazo Province

\section{Resumen}

Se elaboró una propuesta de desarrollo y ordenamiento territorial para el componente económico productivo del cantón Alausí provincia de Chimborazo. Se inició la investigación realizando un análisis de la situación actual del sector productivo; posteriormente, con la ayuda de talleres participativos se identificaron los principales problemas y potencialidades, temas que ayudaron finalmente a la definición de estrategias de desarrollo planteadas en término de programas y proyectos. En conclusión, en cuanto a situación actual, Alausí posee características netamente rurales, el 75,87\% de la población económicamente activa realiza actividades agropecuarias, posee suelos franco arenosos con pendientes que oscilan de 15 a $45^{\circ}$ de inclinación, a pesar de esto son aptos para el desarrollo de actividades agropecuarias, la extensiones de suelo destinadas para producción agropecuaria corresponde al 39\% de la extensión total y sus principales productos son: cebada, maíz, papa y leche fresca. Además se evidencia como principal problema el acceso a la tecnología requiriendo una serie de mejoras para lograr rentabilidad en la producción por lo que se recomienda al Gobierno Municipal de Alausí que implemente los proyectos plasmados en la presente investigación cuyo fin será potenciar el sector económico productivo del cantón y mejorar la calidad de vida de la población.

Palabras claves: Propuesta De Desarrollo, Desarrollo Rural, Estrategias De Desarrollo, Programas De Desarrollo, Sostenibilidad, Componente Economico Productivo, Alausi, Chimborazo.

\section{INTRODUCCIÓN:}

En el Ecuador, el índice de pobreza ha llegado a niveles extremos y en algunos casos alarmantes; considerando que los indicadores de pobreza ${ }^{16}$ y otros factores como la migración, constituyen una herramienta básica en la planificación, evaluación, seguimiento y diseño de políticas sociales (INEC, 2016: 3); ante esta problemática todos los sectores gubernamentales,

${ }^{16}$ La pobreza a nivel nacional se ubicó en $23,7 \%$ y la pobreza extrema en $8,6 \%$. Por su parte la brecha de pobreza se ubicó en 16,9\% y la severidad 9,5\%. (Ecuador en cifras.gob.ec) 
empresariales y constitucionales mantienen la lucha incesante para proporcionar una mejor calidad de vida a toda la población en igualdad de condiciones (Departamento de asuntos económicos y sociales. División de Desarrollo Sostenible. ONU. Programa 21. Capítulo III, 2006:2)

La Constitución de 2008 posiciona a la planificación y a las políticas públicas como instrumentos para la consecución de los Objetivos del Buen Vivir y la garantía de derechos. Según la Carta Magna la planificación tiene por objeto propiciar la equidad social y territorial además de promover la concertación. Para ello, se debe asumir como prioridad la erradicación de la pobreza, la promoción del desarrollo sostenible y la (re)distribución equitativa de los recursos, como condiciones fundamentales para alcanzar el Buen Vivir. (PLAN NACIONAL DE DESARROLLO, 2013)

La construcción de un nuevo modelo de Estado, con énfasis en la estrategia de acumulación y redistribución en el largo plazo (Moreno, 2005:4), comprende desafíos asociados a la territorialización de la políticas públicas (Gallicchio, 2000:13) para reducir brechas de inequidad y satisfacer las necesidades básicas de los territorios y su población; la aplicación de tecnología, innovación y conocimiento; la sustentabilidad ambiental; y, el cambio de la matriz productiva, estos desafíos exigen al Gobierno central y a los Gobiernos Autónomos Descentralizados el diseño y aplicación de mecanismos de coordinación entre las agencias centrales (sectoriales) y las instancias descentralizadas (Ojeda, 2000: 20), de manera que la gestión de los distintos niveles territoriales sea ampliamente concertada.

En este contexto los gobiernos seccionales y las instituciones no gubernamentales como es el caso de la fundaciones internacionales constituyen como los actores principales capaces de generar el desarrollo local sostenible en un determinado sector (Ramón, 2004: 15), a través de la implementación de acciones y estrategias que propicien la producción de bienes y servicios para la generación de efectos como el bienestar de sus habitantes en un ambiente de refuerzo de las identidades y cultura además de ampliación de democracia (Bartra, 2000: 6), de respeto a los derechos humanos y de equidad de género; propiciando como gran resultado general el aumento de las economías de escala y el mejoramiento de la calidad de vida de la población beneficiaria (Andrade, 2016: 5).

\section{METODOLOGÍA}

El trabajo se realizó en el cantón Alausí y el diseño utilizado fue de tipo no experimental con un fuerte componente en el área de diagnóstico, análisis de componente y proyección de actividades. El tipo de investigación es de tipo descriptivo utilizando un muestreo dirigido.

Se realizaron talleres parroquiales con la participación aproximadamente participante en cada taller. 
En la investigación se utilizó el método no experimental para el análisis de diagnóstico por componente mientras que el método transversal se utilizó para recolectar datos en un tiempo único, su propósito fue describir cada una de las variables planteadas.

\section{Técnicas}

Para la presente investigación se emplearon técnicas como: Diagnóstico participativo, Entrevistas a actores claves, lluvias de ideas, Observación directa, técnica de visualización de hechos.

\section{Instrumentos}

Los instrumentos que se utilizaran fueron: Talleres participativos, Guía de entrevista, ficha de campo, encuestas, modelos y esquemas

\section{Metodología}

La investigación se llevó a cabo mediante la recopilación de información primaria recogida en talleres realizados con grupos focales, observación de campo y entrevistas, se contó con la participación activa de los pobladores del cantón. Además, la información también fue obtenida de fuentes primarias y secundarias tales como: Planes de Desarrollo Estratégico, Plan de Desarrollo y Ordenamiento Territorial del Cantón Alausí, Año 2010 - 2014, Sistema Nacional de Información, SIN, Sistema Integrado de Indicadores Sociales del Ecuador, SIISE. Versión 4.5 y del Instituto Nacional de Estadísticas y Censos, INEC.

\section{RESULTADOS}

\section{- Situación Actual del cantón}

Según CNPV, la población de Alausí está constituida por un total de 44089 habitantes, representando el 9,25\% del total de la población la provincia de Chimborazo. Además, el 85,64\% de la población cantonal está asentada en el área rural, significando que es un cantón con características netamente rurales.

\section{- Dinámica de la población}

La densidad poblacional del cantón Alausí es de 27 habitantes por Km², considerando que la media nacional es de 48 habitantes por $\mathrm{Km}^{2}$. En cuanto a género, la población femenina urbana en el año de 1990 representó el 52\% de la población total, en el 2.001 representa el 53\% y para el año 2010 la población femenina representó el $52 \%$ de la población total, lo que hace pensar en una reproducción casi armónica en cuanto a esta estructura, notándose además que la migración no ha afectado mucho a dicha estructura. 


\section{- Migración Interna}

Debido a los limitados recursos productivos existentes dentro del cantón, como el capital, la tierra y el trabajo, han expulsado del campo a una gran cantidad de población ${ }^{17}$, a algunos en forma definitiva y a otros de manera temporal, pero como las ciudades no ofrecen oportunidades de trabajo estable, entonces la migración campo - ciudad, se vuelve, cíclica, es decir, en temporadas de demanda de trabajo (siembras, cosechas) la gente permanece en las comunidades, pero luego, viaja a las ciudades en busca de trabajo, estas duran entre 3 a 6 meses, siendo más frecuentes de julio a septiembre.

En el caso de los más jóvenes, ellos buscan reunir ingresos para establecer sus hogares, separados de sus padres, las ciudades de Riobamba, Machachi, Quito y Cuenca son los destinos en la Sierra; Milagro y Guayaquil, en la Costa. Los hombres encuentran ocupación en la construcción, en la agricultura, el corte de la caña de azúcar, en tiendas y mercados cargando las compras. Por las actividades mencionadas, sus ingresos van de 240 a 360 dólares mensuales, pero también aceptan cualquier trabajo por un jornal de 6 dólares el día. La opción mayoritaria para las mujeres es el trabajo doméstico, que les permite ingresos de 300 a 350 USD mensuales.

\section{Migración Externa}

La migración externa representa el $0,62 \%$ a nivel nacional y el total de migrantes que salieron de la provincia de Chimborazo, es de 8633 personas según datos Censo nacional de Población y Vivienda 2010.

\section{Situación social relacionada con la pobreza}

El nivel de pobreza en Alausí es grande a tal punto de considerarlo como el principal problema a solucionar. Según los indicadores de comparación nacional, la pobreza por Necesidades Básicas Insatisfechas (NBI) es muy alta $87 \%$, quizá la baja productividad de las unidades de producción y sumado a esto el incremento de la población hace que la disponibilidad de recursos sea ínfima. Los indicadores de la situación de pobreza del cantón Alausí, comparados con los de la provincia de Chimborazo están entre los más altos.

\footnotetext{
${ }^{17}$ La migración se produce por la emigración y la inmigración: 1764 casos de migración 19\% área urbana 81\% área rural la causa principal es el trabajo y economía baja. De este total el $68 \%$ son hombres migrantes y el $42 \%$ son mujeres. (PLAN MÉDICO FUNCIONAL: CENTRO DE ATENCIÓN AMBULATORIA ALAUSI. 2012)
} 


\section{Población y empleo}

Según datos del INEC 2010, la población en edad de trabajar (PET) a nivel cantonal es de 33.015 personas que constituyen el 74,88\% de la población total del cantón; en el área urbana es de 5.148 (15.59\% de la PET total), y de 27.867 personas en el área rural (el restante $84.41 \%$ ). La población en edad de trabajar de acuerdo al sexo, según el último censo INEC 2010, se compone de 15.578 hombres y 17.437 mujeres.

\section{Población Económicamente Activa del Cantón Alausí}

Según datos del INEC (Censo 2010), la población económicamente activa del cantón Alausí corresponde a 17158 personas.

\section{Población Ocupada por rama de Actividad}

La población económicamente Activa con mayor grado de participación realizan actividades agropecuarias, con 12170 casos; seguidas por las actividades comerciales y la rama de construcción con 770 y 671 casos respectivamente; mientras que en menor número se registra la actividad extractiva como minas y canteras con apenas 16 casos;la de distribución de agua, alcantarillado y desechos de sólidos con 5 casos; la actividad inmobiliaria y las actividades de organizaciones y órganos extraterritoriales son incipientes apenas con 1 caso cada una.

\section{Actividades Agropecuarias}

La tenencia de la tierra varía según la zona agro-ecológica, es así que en función de la altitud, temperatura, precipitación, los tipos de suelo y relieve, se pueden identificar en dentro del Cantón Alausí tres zonas claramente diferenciadas.

Zona alta (3.200 a $4.600 \mathrm{msnm}$ ). Zona con gran número de quebradas y pendientes que van desde el 15 a $30^{\circ}$ grados, en sectores totalmente escarpados superan los $45^{\circ}$ grados de inclinación, a pesar de todo esto son suelos de buena calidad, generalmente negros con altos contenidos de materia orgánica, textura franca con capacidad de retención de humedad, a esta zona pertenecen las parroquias: Achupallas, Sevilla y Pumallacta.

Zona media (2500 a 3.200 msnm). Esta zona comprende las parroquias de la Matriz Alausí, Guasuntos y Tixán, caracterizada por poseer pendientes no tan inclinadas, casi planas.En esta zona se práctica la asociación de cultivos de manera especial tales como cereales con leguminosas (cebada/arveja, maíz /frejol, habas/maíz) además se practican la rotación de cultivos.

Zona Baja (1250 - 2.500). Comprende áreas con topografía generalmente plana a ondulada, comprendida por las parroquias de Huigra, Sibambe, Multitud y Pistishí, aquí predomina el cultivo de pastizales por 
estar identificada como zona ganadera especialmente para la producción de leche, además aquí se cultivan productos como como frejol, arveja, tomate de carne y plantas frutales.

\section{Uso del Suelo}

Del total de la superficie que tiene el cantón (165833 ha), la mayor parte del territorio está ocupado por áreas destinadas a conservación y protección de tal manera que el páramo ocupa el primer lugar en cuanto a su uso con un total de 60710.11 hectáreas correspondientes al 36.6\% , lo cual constituye un gran potencial para el cantón por la regulación hídrica que estos generan; seguidamente están los cultivos de altura y cultivos/ pasto/ bosque, con un total de 30998.91 hectáreas y 14956.51 correspondientes al $18.7 \%$ y $9 \%$ respectivamente, del territorio cantonal, mientras que en menor hectáreas se encuentran los cultivos de zona cálida con 319.37 hectáreas y plantaciones forestales con un total de 250.96 hectáreas, mismas que corresponden a la zonas de protección o producción.

La agricultura ocupa un total de 36953,79 hectáreas, la misma que engloba cultivos de altura, cultivos permanentes, cultivos de zona templada y cultivos de zona de cálida. y todo tipo de tierra cultivada. El uso pecuario posee una superficie de 13.131,86 ha (7,9 \%), siendo los pastos cultivados en su mayoría de tipo pasto azul, raygrass y trébol blanco.

\section{Características Pecuarias}

Respecto al ganado vacuno, de un total de 38210 cabezas de ganado vacuno existentes en el cantón; 33622 cabezas son criollos, 4365 cabezas son mejorados sin registros, 12 cabezas se registran como mejorados con registro, 29 cabezas se registran como pura sangre de carne y definitivamente no existen animales pura sangre de leche, ni de doble propósito. Del total de cabezas de ganado vacuno existentes en el cantón, se registran 9676, que se encuentran en producción dando y estas producen un total de 54960 litros de leche diarios a nivel cantonal.

En cuanto a ganado porcino existente a nivel cantonal se registra un total 21.826 especies, de los cuales el $90 \%$ son criollos y apenas el $10 \%$ presentas características mejoradas.

Con características predominantes se encuentra el ganado ovino a nivel cantonal, registrándose un total 56.435 ejemplares de los cuales el 92\% son criollos y apenas el 8\% son mejorados.

En lo que tiene que ver a aves existen un total de 53.581 aves criadas a nivel del campo y un total de 6256 aves criadas en planteles avícolas, considerándose como una media cantonal este valor ya que este tipo de producción se lo realiza como mínimo 3 veces al año y finalmente respecto a la producción de cuyes y conejos de acuerdo a información levantada en el 
Censo Agropecuario y reflejada en cuadro anteriormente detallado, se tiene conocimiento que existen un total de 2963 conejos y 63393 cuyes a nivel cantonal.

\section{Valor Agregado Bruto por sectores económicos}

El valor agregado bruto en el cantón Alausí al año 2012 asciende a 55.952,46 USD, evidenciándose un incremento del 48,03\% en relación al año 2007; de igual manera a nivel de los sectores económicos, se centra el $73,93 \%$ del VAB en el sector terciario (servicios), seguido del sector primario con el 25,80\% y el sector secundario con el 0,27\%. Evidenciándose un decrecimiento de 17,42 en el sector primario, específicamente en lo que respecta agricultura, ganadería, silvicultura y pesca; al contrario de los sectores secundario y terciario los cuales presentan un incremento de 0,15 y 17,28 respectivamente. A nivel de las ramas económicas se destaca la agricultura, ganadería, silvicultura y pesca con el 25,69\%, y a nivel de servicios la enseñanza con el 25,10\% y la administración pública con 14,41\% evidenciándose que el cantón Alausí tiene concentrada las actividades económicas agropecuarias además de la enseñanza y la administración pública.

\section{Actividad Forestal}

Actualmente no existe un catastro actualizado del número de familias que se dediquen a la actividad forestal, tampoco se conoce cuantas zonas de bosques comerciales y para conservación existen a nivel cantonal. Sin embargo según información registrada en publicaciones de ECOCIENCIA, 2010, se prescribe que el 0.15\%, equivalentes a 250,9 has del territorio cantonal serían plantaciones forestales.

\section{Riego}

En el cantón Alausí, existen 255 captaciones inventariadas de agua con fines agrícolas, mismas se encuentran implantadas en terrenos de propiedad comunitaria y privada, en su mayoría no protegidas al intemperismo y a la contaminación, lo que determina que la calidad físicaquímica y bacteriológica no sea la más adecuada y que su constancia sea diferente según la época del año.

De acuerdo al Inventario Hídrico de la Provincia de Chimborazo (2009), el cantón cuenta con 472 Sistemas de Agua, de éstos 217 corresponden a consumo humano, 2 son abrevaderos, 253 son de riego.

\section{Seguridad y Soberanía Alimentaria}

En el cantón la Soberanía Alimentaria forma parte importante de los derechos que tiene la ciudadanía para asegurar el sistema agroalimentario, 
conocer los factores de producción dentro de cada sector, comunidad y hogar, por lo que es trascendental conocer que la agricultura familiar campesina de orientación agroecológica en el cantón se desarrolle de forma autónoma y con cierto grado de equidad, se conoce con certeza que en 7 de las 9 parroquias se encuentran personas que ponen en práctica formas de soberanía alimentaria dentro de cada uno de sus hogares, es así que, se ha visto este tipo en emprendimientos en las parroquias de: Achupallas, Guasuntos, Tixán, Pistishí Sibambe donde la población posee sus pequeños huertos familiares para su autoconsumo y generalmente siembra productos como: melloco, papa, cebada, trigo, maíz, fréjol, haba, frutales, hortalizas, no así, en las demás parroquias del cantón, garantizando de esta manera el derecho humano a la provisión permanente de alimentos sanos, nutritivos, suficientes y culturalmente apropiados.

\section{Turismo Sostenible}

Alausí es poseedor de un alto potencial turístico, basados en varios inventarios turísticos que rezan la existencia de aproximadamente 10 atractivos naturales y culturales (ESPOCH. 2010) que no están siendo aprovechados por falta de aplicación de las políticas públicas de promoción turística dentro de este territorio y una insipiente preparación de los prestadores de servicios dentro de la actividad.

\section{Identificación, Análisis y priorización de problemas y potencialidades del componente económico productivo}

Esta información fue levantada a partir de los talleres de diagnóstico levantados a nivel cantonal, donde se pudo conversar con la población acerca de los principales problemas y potencialidades que poseen en su territorio y que de cierta manera les beneficia o perjudica el momento de emprender algún proyecto.

Con el diagnóstico económico levantado en el cantón se plantea estrategias de desarrollo que a futuro promuevan oportunidades productivas para la población, propiciando el desarrollo económico local. Respecto al análisis de los problemas se identifica que el problema con mayor prioridad a atender corresponde a la "Falta de Tecnificación"; la baja productividad agrícola, derivada del escaso conocimiento y la limitada educación, es una de las principales causas que postergan el desarrollo económico y social a nivel cantonal.

Al ser el cantón Alausí considerado como un cantón netamente agropecuario y sabiendo que el riego es la fuente principal para la producción y demás encadenamientos productivos, saber que la falta de organización de los productores para acceder a Asistencia técnica provoca que el sector agro productivo tienda a decaer. 
La ausencia de tecnología específicamente en el sector de la pequeña agricultura (campo), hace que los cultivos y micro emprendimientos en general pierdan competitividad a nivel provincial y regional precisamente por los reducidos sistemas de comercialización que se presenten al carecer de un producto ideal para el mercado, además el no contar con una tecnología adecuada hace que el productor maximice la mano de obra utilizada en las labores provocando que los costos de producción se eleven provocando de manera general que los productores abandonen sus campos y por ende se presente el fenómeno de la migración.

Tabla1. Principales problemas y potencialidades identificadas en el cantón

\begin{tabular}{|c|c|c|}
\hline VARIABLES & PROBLEMAS & POTENCIALIDADES \\
\hline \multirow{2}{*}{ Trabajo y empleo } & Migración de la Población & \multirow{2}{*}{$\begin{array}{l}\text { Personal profesional con alta } \\
\text { formación académica }\end{array}$} \\
\hline & Escasas fuentes de trabajo & \\
\hline \multirow{4}{*}{$\begin{array}{l}\text { Actividades } \\
\text { Agroproductivas }\end{array}$} & Débil Organización de la población & $\begin{array}{l}\text { Conocimiento ancestral en } \\
\text { agricultura orgánica }\end{array}$ \\
\hline & $\begin{array}{c}\text { Disminución de la población dedicada } \\
\text { actividades agrícolas }\end{array}$ & $\begin{array}{c}\text { Población Económicamente activa } \\
\text { Joven }\end{array}$ \\
\hline & Falta de Asistencia Técnica & \multirow{2}{*}{$\begin{array}{l}\text { Disponibilidad de tierras con aptitud } \\
\text { agrícola }\end{array}$} \\
\hline & Perdida de buenas prácticas agrícolas & \\
\hline Factores Productivos & Manejo inadecuado de vertientes & $\begin{array}{c}\text { Presencia de proyectos del GAD } \\
\text { Provincial y ONG para proveer el } \\
\text { riego a sectores que carecen de este } \\
\text { recurso }\end{array}$ \\
\hline \multirow{3}{*}{ Principales Productos } & $\begin{array}{c}\begin{array}{c}\text { Reducidos sistemas de } \\
\text { comercialización }\end{array} \\
\end{array}$ & Diversidad de productos agrícolas \\
\hline & $\begin{array}{l}\text { Limitado acceso a la tecnología en los } \\
\text { procesos productivos }\end{array}$ & \multirow{2}{*}{$\begin{array}{l}\text { Alta producción de leche } \\
\text { Riqueza del cantón en recursos } \\
\text { forestales }\end{array}$} \\
\hline & Deterioro de los ecosistemas & \\
\hline \multirow{2}{*}{$\begin{array}{l}\text { Infraestructura de } \\
\text { apoyo a la producción }\end{array}$} & $\begin{array}{l}\text { Falta de infraestructura para generar } \\
\text { valor agregado }\end{array}$ & \multirow[t]{2}{*}{ Disponibilidad de Fuentes hídricas } \\
\hline & Falta de infraestructura para riego & \\
\hline $\begin{array}{c}\text { Seguridad } \\
\text { Alimentaria }\end{array}$ & Elevados costos de producción & $\begin{array}{c}\text { Tierras fértiles, aptas para producir } \\
\text { una diversidad de productos }\end{array}$ \\
\hline Vulnerabilidad & $\begin{array}{c}\text { Suelos con vulnerabilidad a fenómenos } \\
\text { naturales en algunas comunidades }\end{array}$ & $\begin{array}{c}\text { Presencia de la Secretaría Nacional de } \\
\text { Riesgos }\end{array}$ \\
\hline Turismo & $\begin{array}{l}\text { Falta de promoción y difusión de los } \\
\text { atractivos naturales y culturales }\end{array}$ & $\begin{array}{c}\text { Cantón con innumerables atractivos } \\
\text { turísticos, arqueológicos y } \\
\text { patrimoniales } \\
\end{array}$ \\
\hline
\end{tabular}

Fuente: Diagnóstico Participativo Cantonal 2015.

Elaborado por: Ángela Paulina Rivera Riera

Estrategias de desarrollo. En base al análisis FODA levantado en forma participativa con la población se procedió a la construcción de la propuesta estratégica de desarrollo misma que se hará operativa mediante la 
definición de programas y proyectos acorde a las prioridades identificadas y priorizadas por la población.

Análisis del Componente Económico Es importante mencionar que la población del cantón en su mayoría son jóvenes ${ }^{18}$, lo que significa que existe o existirá a futuro un gran potencial respecto a mano de obra en edad productiva,. El sector primario, básicamente la agricultura y ganadería es el medio de vida generalizado para la población del cantón Alausí, seguido con un menor porcentaje de las actividades comerciales y posteriormente de la construcción, esto a nivel rural mientras que en el sector urbano existe una concentración en el sector de servicios generales. Sin embargo, la inestabilidad del mercado, respecto a precios del ganado mayor y menor origina grandes pérdidas a las economías familiares que subsisten de esta actividad, ya que los mismos son impuestos por los famosos intermediarios.

La principal actividad dentro de la agricultura está dada por la elevada parcelación ${ }^{19}$ y la inversión alta que se requiere para poder adquirir tecnología apropiada con el fin de llegar a producir adecuadamente. Por otro lado, el fortalecimiento del turismo a nivel cantonal es una de las medidas a proponer para potenciar al cantón como un eje importante a la hora de posibilitar la estrategia de diversificación de la economía, mencionar también que la actividad industrial es mínima a nivel cantonal excluyendo lagunas empresas de procesamiento de lácteos que se encuentran ubicadas en determinadas parroquias.

\footnotetext{
${ }^{18}$ La mayor parte de la población se encuentra en el grupo de edad entre 10 a 14 años que representa el 13,33\% de la población total. La población estudiantil, que corresponde a los grupos de edad entre 5 a 9 años, representan el 13.09\%, entre 10 a 14 años el 13,33\% y de 15 a 19 años el 10,68\%. (INEC

VI Censo de Población y Vivienda año 2010)

${ }^{19}$ El cultivo que más se destaca es la cebada con 26.134 UPA's y 19.420 hectáreas sembradas. El tamaño de las UPA's para monocultivos transitorios es básicamente de menos de 50 hectáreas, ya que existen 108.982 UPA's y 70.216 hectáreas sembradas. (III Censo Nacional Agropecuario, 2002)
} 
TABLA 2. Análisis estratégico del Sistema Económico Productivo.

\begin{tabular}{|c|c|c|c|}
\hline PARA POTENCIAR & PARA APROVECHAR & PARA DISMINUIR & $\begin{array}{c}\text { PARA } \\
\text { EQUILIBRAR }\end{array}$ \\
\hline $\begin{array}{c}\text { La gestión continua ante } \\
\text { entidades } \\
\text { públicas y privadas vinculadas } \\
\text { con el } \\
\text { desarrollo del sector } \\
\text { agropecuario del cantón. }\end{array}$ & $\begin{array}{l}\text { El empeño de mejorar la } \\
\text { matriz productiva }\end{array}$ & & $\begin{array}{l}\text { La presencia de } \\
\text { intermediarios en } \\
\text { los mercados } \\
\text { locales. }\end{array}$ \\
\hline $\begin{array}{l}\text { El nivel organizacional de los } \\
\text { productores. }\end{array}$ & $\begin{array}{l}\text { El apoyo de OG y ONG } \\
\text { presentes en el cantón } \\
\text { encaminadas al } \\
\text { fortalecimiento de líderes y } \\
\text { lideresas. }\end{array}$ & $\begin{array}{c}\text { El bajo nivel } \\
\text { organizativo presente en } \\
\text { la población, resultado } \\
\text { de análisis participativo } \\
\text { cantonal. }\end{array}$ & \\
\hline $\begin{array}{l}\text { La diversificación de productos } \\
\text { agrícolas que se producen } \\
\text { dentro del cantón. }\end{array}$ & $\begin{array}{c}\text { La variedad de pisos } \\
\text { climáticos presentes dentro } \\
\text { del cantón Alausí. }\end{array}$ & $\begin{array}{l}\text { El posicionamiento de } \\
\text { otros mercados sobre } \\
\text { nuestro mercado local. }\end{array}$ & $\begin{array}{l}\text { Sobre oferta de } \\
\text { productos dada } \\
\text { por parte de } \\
\text { asociaciones. }\end{array}$ \\
\hline $\begin{array}{c}\text { El acceso a Asistencia técnica } \\
\text { y tecnología especializada. }\end{array}$ & $\begin{array}{c}\text { El empeño de instituciones } \\
\text { públicas para utilizar } \\
\text { tecnología agropecuaria } \\
\text { apropiada. }\end{array}$ & $\begin{array}{c}\text { EL bajo nivel de } \\
\text { tecnificación presente } \\
\text { en la producción } \\
\text { agrícola. }\end{array}$ & \\
\hline $\begin{array}{l}\text { Las unidades de producción } \\
\text { agropecuaria que actualmente } \\
\text { se encuentren sub utilizadas. }\end{array}$ & $\begin{array}{c}\text { La Asistencia técnica que } \\
\text { brinda las diversas } \\
\text { instituciones presentes en el } \\
\text { cantón con fines productivos. }\end{array}$ & Las UPAS subutilizadas & \\
\hline $\begin{array}{l}\text { Los encadenamientos } \\
\text { productivos y el conocimiento } \\
\text { ancestral en agricultura } \\
\text { orgánica }\end{array}$ & $\begin{array}{l}\text { Apoyo económico a los } \\
\text { pequeños } \\
\text { productores por parte de } \\
\text { entidades del Gobierno. }\end{array}$ & $\begin{array}{l}\text { Las malas prácticas } \\
\text { agrícolas que ocasionan } \\
\text { el deterioro de los } \\
\text { ecosistemas } \\
\text { productivos. }\end{array}$ & $\begin{array}{c}\text { El } \\
\text { posicionamiento } \\
\text { de otros } \\
\text { mercados sobre } \\
\text { nuestro mercado } \\
\text { local. }\end{array}$ \\
\hline $\begin{array}{l}\text { La promoción, difusión y } \\
\text { servicios turísticos presentes } \\
\text { dentro del cantón }\end{array}$ & $\begin{array}{l}\text { El potencial turístico con el } \\
\text { que cuenta el cantón. }\end{array}$ & $\begin{array}{c}\text { El deterioro del } \\
\text { Ecosistema Productivo - } \\
\text { Turístico. }\end{array}$ & $\begin{array}{l}\text { La afluencia } \\
\text { turística al cantón } \\
\text { Alausí }\end{array}$ \\
\hline La mano de obra calificada & & & $\begin{array}{l}\text { La fuga de mano } \\
\text { de obra fuera del } \\
\text { cantón. }\end{array}$ \\
\hline $\begin{array}{l}\text { El recurso forestal presente en } \\
\text { el cantón. }\end{array}$ & & $\begin{array}{l}\text { La tala indiscrimada de } \\
\text { árboles. }\end{array}$ & \\
\hline
\end{tabular}

Elaborado por: Ángela Paulina Rivera Riera.

Escenarios de Desarrollo

A continuación se presenta varios escenarios de desarrollo respecto a los acontecimientos sucedidos en el campo productivo hasta la actualidad para seguidamente presentar el posible escenario tendencial y el escenario futuro si se tomara en cuenta las recomendaciones planteadas en la presente propuesta. 
TABLA 3. Escenarios de desarrollo para el cantón Alausí

\begin{tabular}{|c|c|c|}
\hline ESCENARIO PASADO & ESCENARIO ACTUAL & ESCENARIO FUTURO \\
\hline $\begin{array}{l}\text { No existía una zonificación } \\
\text { agro productiva y de uso del } \\
\text { suelo en el cantón }\end{array}$ & $\begin{array}{c}\text { Se cuenta con una zonificación } \\
\text { de uso de suelo solo en la } \\
\text { matriz cantonal. }\end{array}$ & $\begin{array}{c}\text { Contar con una zonificación agro } \\
\text { productiva y de suelo a nivel } \\
\text { cantonal }\end{array}$ \\
\hline $\begin{array}{l}\text { Los productores no utilizaban } \\
\text { semilla certificada para sus } \\
\text { siembras. }\end{array}$ & $\begin{array}{l}\text { La utilización de semilla } \\
\text { certificada sigue siendo nula } \\
\text { a nivel cantonal. }\end{array}$ & $\begin{array}{l}\text { Por lo menos el } 80 \% \text { de los } \\
\text { productores utilizan semilla } \\
\text { certificadas en sus siembras. }\end{array}$ \\
\hline $\begin{array}{l}\text { Las ONGs tenían mayor } \\
\text { injerencia en capacitación } \\
\text { agrícola, incluso más que los } \\
\text { organismos gubernamentales. }\end{array}$ & $\begin{array}{l}\text { Actualmente existe un bajo } \\
\text { acceso a capacitación técnica } \\
\text { por parte de ONGS y } \\
\text { gubernamentales. }\end{array}$ & $\begin{array}{l}\text { Se brinde capacitación constante las } \\
\text { nuevas técnicas de cultivos y acceso } \\
\text { a nuevas tecnologías. }\end{array}$ \\
\hline $\begin{array}{l}\text { El 70,8\% de la población } \\
\text { dedicada a la agricultura } \\
\text { aplicaban fertilización y control } \\
\text { fitosanitario sin criterio técnico. }\end{array}$ & $\begin{array}{l}\text { El 100\% de agricultores aplica } \\
\text { de forma empírica los } \\
\text { productos agroquímicos en } \\
\text { todas las etapas de cultivo. }\end{array}$ & $\begin{array}{c}\text { Incentivar en los agricultores la } \\
\text { utilización de productos } \\
\text { agroecológicos. }\end{array}$ \\
\hline $\begin{array}{c}\text { La siembra de productos } \\
\text { andinos eran prioritarios en la } \\
\text { producción familiar }\end{array}$ & $\begin{array}{l}\text { Se ha perdido en un } 70 \% \text { la } \\
\text { siembra de productos andinos. }\end{array}$ & $\begin{array}{l}\text { Recuperar progresivamente la } \\
\text { siembra de semillas andinas y } \\
\text { fortalecer la soberanía alimentaria }\end{array}$ \\
\hline $\begin{array}{l}\text { No existían normas de } \\
\text { conservación de suelo. }\end{array}$ & $\begin{array}{l}\text { No existen proyectos y estudios } \\
\text { que propicien la conservación } \\
\text { de suelos, especialmente en } \\
\text { pendientes mayores al 30\%. }\end{array}$ & $\begin{array}{l}\text { Se cuente con estudios y proyectos } \\
\text { de conservación de suelos y áreas } \\
\text { con pendientes mayores al } 30 \% .\end{array}$ \\
\hline Escaso número de ganado & $\begin{array}{c}\text { El 80\% de ganado mayor y } \\
\text { menor presenta características } \\
\text { criollas }\end{array}$ & $\begin{array}{c}\text { El } 70 \% \text { de ganado vacuno, porcino } \\
\text { y ovino tiene características } \\
\text { mejoradas. }\end{array}$ \\
\hline $\begin{array}{c}\text { La mayoría de productores } \\
\text { utilizaban pastos comunes para } \\
\text { alimentar a sus ganados }\end{array}$ & $\begin{array}{l}\text { Apenas un } 15 \% \text { de los } \\
\text { productores utilizan mezclas } \\
\text { forrajeras certificadas para la } \\
\text { alimentación de su ganado. }\end{array}$ & $\begin{array}{l}\text { El 80\% de la población utilizan } \\
\text { mezclas forrajeras eficaces para } \\
\text { alimentación del ganado. }\end{array}$ \\
\hline $\begin{array}{c}\text { El sistema de riego por } \\
\text { gravedad era el más utilizado } \\
\text { por los agricultores. }\end{array}$ & $\begin{array}{l}\text { Se sigue utilizando el mismo } \\
\text { sistema de riego. }\end{array}$ & $\begin{array}{l}\text { Implementar en mayor porcentaje } \\
\text { los sistemas de riego por aspersión. }\end{array}$ \\
\hline $\begin{array}{l}\text { Perdida de cultivos por } \\
\text { prolongación del invierno. }\end{array}$ & $\begin{array}{c}\text { Pérdidas de cultivos debido a } \\
\text { una } \\
\text { prolongada sequia }\end{array}$ & $\begin{array}{l}\text { Implementar tanques reservorios de } \\
\text { agua (siembra de agua) en zonas } \\
\text { críticas del cantón, especialmente } \\
\text { en meses secos. }\end{array}$ \\
\hline $\begin{array}{l}\text { La promoción turística de los } \\
\text { atractivos del cantón no es parte } \\
\text { de la política pública. }\end{array}$ & $\begin{array}{l}\text { Carencia de facilidades y } \\
\text { promoción turística. }\end{array}$ & $\begin{array}{c}\text { Se contara con infraestructura } \\
\text { turística adecuada y personal } \\
\text { capacitado para posicionar la marca } \\
\text { Alausí destino del mundo. }\end{array}$ \\
\hline $\begin{array}{l}\text { Los productos primarios eran } \\
\text { vendidos en mercados } \\
\text { intercantonales }\end{array}$ & $\begin{array}{l}\text { La presencia de intermediarios } \\
\text { no permite que existan buenos } \\
\text { sistemas de comercialización. }\end{array}$ & $\begin{array}{c}\text { Se cuenta con buenos sistemas de } \\
\text { comercialización- acceso a } \\
\text { mercados interprovinciales. }\end{array}$ \\
\hline $\begin{array}{l}\text { La leche era utilizada solo para } \\
\text { beneficio familiar. }\end{array}$ & $\begin{array}{l}\text { La mayor parte de la leche se } \\
\text { acopia y se vende a } \\
\text { intermediarios para que sea } \\
\text { procesada fuera del cantón. }\end{array}$ & $\begin{array}{l}\text { Se cuenta con infraestructura que } \\
\text { permita generar valor agregado a la } \\
\text { leche dentro del cantón. }\end{array}$ \\
\hline
\end{tabular}

Fuente: Diagnóstico participativo cantonal 2015

Elaborado por: Ángela Paulina Rivera Riera 


\section{Modelo de desarrollo Deseado. Fomento Productivo}

La propuesta económica está basada a mejorar la producción agrícola y pecuaria, por ser la principal actividad a la que se dedican los habitantes de Alausí. Uno de los apoyos más importantes en el sector agrícola, es el sistema de riego que dispone un territorio, mismo que en su mayor parte es utilizado por gravedad, sistema que no ofrece un aprovechamiento del uso del agua, por lo tanto se plantea cambiar el sistema progresivamente a riego por goteo o aspersión.

\section{Turismo}

En el aspecto turístico, se deberá determinar circuitos turísticos, así como también aprovechar el potencial de las diferentes zonas y parroquias.

\section{Situación óptima deseada}

Se mejorará los sistemas de comercialización y se inician procesos de mejoramiento genético en ganado mayor y menor con apoyo de diferentes instituciones. Los productores tienen acceso a semillas de pasto certificadas, mismas que les permitirá mejorar su producción.

Se ejecutan procesos de capacitación que permitan fortalecer el campo productivo y artesanal.

\section{Infraestructura de apoyo a la producción}

Implementación de infraestructura y mejoramiento de los sistemas de agua para regadío. Se contará con infraestructura y tecnología de punta para el proceso de acopio y procesamiento de la leche y con infraestructura adecuada que permita a los productores desarrollar adecuados sistemas de comercialización.

\section{Infraestructura de turismo}

Se incrementa la afluencia de turistas nacionales y regionales como resultado de una promoción y difusión de sus atractivos turísticos liderada por el Gobierno Municipal de Alaus 
Tabla 3.Propuesta de Desarrollo

\begin{tabular}{|c|c|c|c|c|c|c|c|c|}
\hline PP & POTENCIALIDAD & OBJETIVO ESTRATEGICO & $\begin{array}{l}\text { PRIORIDAD } \\
\text { NACIONAL }\end{array}$ & $\begin{array}{c}\text { 0BJETIVO } \\
\text { BV }\end{array}$ & $\begin{array}{l}\text { COMPETENCIA } \\
\text { EN RELACION } \\
\text { CON OTROS } \\
\text { NIVELES DE } \\
\text { GOBIERNO }\end{array}$ & INDICADOR & META & $\begin{array}{l}\text { POLITICA PUBLICA } \\
\text { TERRITORIALIZADA }\end{array}$ \\
\hline \multirow{3}{*}{ 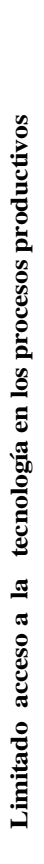 } & \begin{tabular}{|c|} 
Cantón con \\
caracteristicas netamente \\
agropecuarias/Diversida \\
d de pisos climaticos.
\end{tabular} & \multirow{2}{*}{\begin{tabular}{|} 
Incentivar la producción y la \\
competitividad de los sistemas \\
agroproductivos mediante el \\
desarrollo de una producción \\
sostenible con infraestructura \\
adecuada, inclusión social y \\
justicia económica garantizando la \\
seguridad alimentara de las \\
familias del cantón Alausí hasta el \\
año 2019 .
\end{tabular}} & \multirow{3}{*}{$\begin{array}{l}\text { Cambio de la Matriz } \\
\text { productiva para el } \\
\text { pleno empleo y el } \\
\text { trabajo digno }\end{array}$} & \multirow{3}{*}{$\begin{array}{l}\text { Objetivo } 10 . \\
\text { Impulsar la } \\
\text { transformació } \\
\text { n de la matriz } \\
\text { productiva }\end{array}$} & \multirow{3}{*}{$\begin{array}{c}\text { De manera concurrente } \\
\text { con los regionales y } \\
\text { provinciales, definir } \\
\text { estrategias } \\
\text { participativas, } \\
\text { fortalecimiento de } \\
\text { cadenas productivas. } \\
\text { Generación de redes } \\
\text { de comercialización. } \\
\text { Gestión del turismo }\end{array}$} & \multirow{2}{*}{\begin{tabular}{|} 
1. Numero de \\
procesos \\
productivos \\
implementados. \\
2. Porcentaje \\
de ingresos \\
derivados de \\
atividades agrícolas \\
y pecuarias \\
3. Número de \\
familias atendidas \\
con asistencia \\
técnica
\end{tabular}} & \begin{tabular}{|}
30 procesos \\
productivos \\
implementados a \\
finales del año \\
2019
\end{tabular} & $\begin{array}{l}\text { Impulsar la inclusión y la redistribución de los } \\
\text { factores y recursos productivos existentes en el } \\
\text { cantón, promoviendo la agricultura sostenible. }\end{array}$ \\
\hline & $\begin{array}{l}\text { Alta disponibilidad de } \\
\text { fuentes hídricas dentro } \\
\text { del cantón }\end{array}$ & & & & & & $\begin{array}{c}5 \text { sistemas de } \\
\text { riego } \\
\text { rehabilitados } \\
\text { dentro del cantón } \\
\text { a finales del } 2019\end{array}$ & $\begin{array}{l}\text { Gestionar la implementación de programas y } \\
\text { proyectos que permitan la rehabilitación de } \\
\text { sistemas de riego que por falta de inversión se } \\
\text { hallan deteriorados }\end{array}$ \\
\hline & $\begin{array}{c}\text { Cantón con } \\
\text { innumerables atractivos } \\
\text { turísticos, arqueológicos } \\
\text { y patrimoniales }\end{array}$ & $\begin{array}{c}\text { Coordinar los esfuerzos públicos, } \\
\text { privados y comunitarios para el } \\
\text { desarrollo del turismo sostenible } \\
\text { dentro del cantón Alausí. }\end{array}$ & & & & $\begin{array}{l}\text { 1. Porcentaje de } \\
\text { turistas nacionales y } \\
\text { extrangeros que } \\
\text { ingresan al cantón. }\end{array}$ & $\begin{array}{l}\text { Incrementado un } \\
70 \% \text { de afluencia } \\
\text { turistica al cantón } \\
\text { Alausí a finales } \\
\text { del } 2019\end{array}$ & $\begin{array}{l}\text { Diversificar y ampliar la oferta turística del } \\
\text { cantón, orientada hacia el desarrollo de } \\
\text { productos turísticos innovadores que } \\
\text { respondan a las exigencias de la demanda } \\
\text { nacional e internacional. }\end{array}$ \\
\hline
\end{tabular}


Tabla 4. Programas y Proyectos propuestos para el eje productivo

\begin{tabular}{|c|c|c|c|c|c|c|c|}
\hline \begin{tabular}{|l|} 
PRO \\
G.
\end{tabular} & PROYECTO & OBJETIVO & \begin{tabular}{|c|} 
PRESUPUESTO \\
USD
\end{tabular} & $\begin{array}{c}\text { AÑO DE } \\
\text { EJECUCION }\end{array}$ & INDICADOR DE GESTION & ACTORES INVOLUCRADOS & $\begin{array}{c}\text { FUENTES DE } \\
\text { FINANCIAMIENTO }\end{array}$ \\
\hline \multirow{10}{*}{ 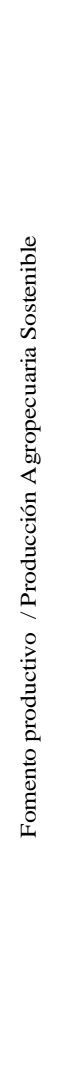 } & $\begin{array}{l}\text { Incorporación a la producción de semillas } \\
\text { certificadas }\end{array}$ & $\begin{array}{l}\text { Mejorar la producción agrícola a } \\
\text { travez de la dotación de semillas } \\
\text { certificada }\end{array}$ & $50.000,00$ & $1,2,3$ & $\begin{array}{l}\text { Número de emprendimientos } \\
\text { implementados a nivel cantonal }\end{array}$ & $\begin{array}{l}\text { GAD Municipales, GADs } \\
\text { Parroquiales,MAGAP, Comunidades } \\
\text { del cantón Alausí, Fundación SWISAID }\end{array}$ & \begin{tabular}{|c} 
GADs Provincial, Cantonal y \\
Parroquial,Visión Mundial, \\
Fundación SWISAID. \\
\end{tabular} \\
\hline & Recuperación de semillas andinas & $\begin{array}{l}\text { Contribuir a la soberanía alimentaria } \\
\text { y al buen vivir }\end{array}$ & $20.000,00$ & 1 & $\begin{array}{l}\text { Número de semillas andinas } \\
\text { recuperadas }\end{array}$ & $\begin{array}{l}\text { GAD Municipales, GADs } \\
\text { Parroquiales,Comunidades del cantón } \\
\text { Alausí,Fundación SWISAID. }\end{array}$ & $\begin{array}{l}\text { GADs Provincial, Cantonal y } \\
\text { Parroquial,Visión Mundial, } \\
\text { Fundación SWISAID. }\end{array}$ \\
\hline & $\begin{array}{l}\text { Implementación de huertos familiares } \\
\text { agroecológicos }\end{array}$ & $\begin{array}{l}\text { Fometar la agricultura tradicional } \\
\text { evitando la utilización de } \\
\text { agroquímicos }\end{array}$ & $50.000,00$ & 1 & $\begin{array}{l}\text { Número de huertos agroecologicos } \\
\text { implementados }\end{array}$ & $\begin{array}{l}\text { GAD Municipales, GADs } \\
\text { Parroquiales,Comunidades del cantón } \\
\text { Alausí,Fundación SWISAID. }\end{array}$ & \begin{tabular}{|c|} 
GADs Provincial, Cantonal y \\
Parroquial,Visión Mundial, \\
Fundación SWISAID. \\
\end{tabular} \\
\hline & $\begin{array}{l}\text { Talleres de capacitación a los productores } \\
\text { sobre nuevas tecnologías para la producción } \\
\text { agrícola sustentable }\end{array}$ & $\begin{array}{l}\text { Educar a la población en nuevas } \\
\text { técnicas agrícolas con enfasis al } \\
\text { mejoramiento de la producción }\end{array}$ & $10.000,00$ & 1 & Número de talleres realizados & $\begin{array}{l}\text { GAD Municipales, GADs } \\
\text { Parroquiales,MAGAP, Comunidades } \\
\text { del cantón Alausí. }\end{array}$ & $\begin{array}{c}\text { GADs Provincial, Cantonal y } \\
\text { Parroquial. }\end{array}$ \\
\hline & $\begin{array}{l}\text { Mejoramiento genético de ganado vacuno, } \\
\text { porcino y ovino. }\end{array}$ & $\begin{array}{l}\text { Incrementar la producción de leche y } \\
\text { carne a travez d el mejoramiento } \\
\text { genetico }\end{array}$ & $50.000,00$ & 2 & $\begin{array}{l}\% \text { de ganado mejorado presente } \\
\text { en el cantón }\end{array}$ & $\begin{array}{l}\text { GAD Municipales, GADs } \\
\text { Parroquiales,MAGAP, Comunidades } \\
\text { del cantón Alausí. }\end{array}$ & $\begin{array}{l}\text { GADs Provincial, Cantonal y } \\
\text { Parroquial, MAGAP. }\end{array}$ \\
\hline & $\begin{array}{l}\text { Implementación de campañas de control } \\
\text { sanitario en ganado mayor }\end{array}$ & \begin{tabular}{|l|} 
Mejorar la producción a travez de la \\
implemnetación de campañas de \\
desparasitación y vitaminización.
\end{tabular} & 25000,00 & $1,2,3,4,5$ & $\begin{array}{l}\text { Número de campañas } \\
\text { implementadas a nivel cantonal }\end{array}$ & $\begin{array}{l}\text { GAD Municipales, GADs } \\
\text { Parroquiales,MAGAP, Comunidades } \\
\text { del cantón Alausí. }\end{array}$ & $\begin{array}{l}\text { GADs Provincial, Cantonal y } \\
\text { Parroquial, MAGAP }\end{array}$ \\
\hline & $\begin{array}{l}\text { Construcción de } 3 \text { centros de acopio para } \\
\text { granos secos }\end{array}$ & $\begin{array}{l}\text { Establecer zonas de comercio al por } \\
\text { mayor de granos secos }\end{array}$ & $180.000,00$ & $2,3,4$ & $\begin{array}{l}\text { Número de centros de acopio } \\
\text { implementados }\end{array}$ & $\begin{array}{l}\text { GAD Municipales, GADs } \\
\text { Parroquiales,MAGAP, Comunidades } \\
\text { del cantón Alausí. }\end{array}$ & $\begin{array}{l}\text { GADs Provincial, Cantonal y } \\
\text { Parroquial, MAGAP }\end{array}$ \\
\hline & Insentivar la creación de bancos comunitarios & $\begin{array}{l}\text { Generar el acceso a créditos } \\
\text { directos a los agricultores }\end{array}$ & 5000,00 & 1 & $\begin{array}{l}\text { Número de creditos otorgados a } \\
\text { productores }\end{array}$ & $\begin{array}{l}\text { GAD Municipales, GADs Parroquiales, } \\
\text { CEPESIU, Comunidades del cantón } \\
\text { Alausí. }\end{array}$ & $\begin{array}{c}\text { CEPESIU, GADs Cantonal y } \\
\text { Parroquial. }\end{array}$ \\
\hline & $\begin{array}{l}\text { Proyectos de siembra y cosecha de Agua de } \\
\text { lluvia en las parroquias de Tixan, Achupallas } \\
\text { y Guasuntos. }\end{array}$ & $\begin{array}{l}\text { Contar con fuentes de reserva de } \\
\text { agua en zonas con déficit hídrico }\end{array}$ & $200.000,00$ & $1,2,3$ & \begin{tabular}{|l|} 
Número de tanques reservorios de \\
agua para regadío
\end{tabular} & $\begin{array}{l}\text { GAD Municipales, GADs } \\
\text { Parroquiales,MAGAP, Comunidades } \\
\text { del cantón Alausí. }\end{array}$ & $\begin{array}{c}\text { GADs Provincial, Cantonal y } \\
\text { Parroquial. }\end{array}$ \\
\hline & Proyectos de rotación de cultivos & $\begin{array}{l}\text { Mejorar la calidad de suelos a travez } \\
\text { de la rotación de cultivos }\end{array}$ & $300.000,00$ & $1,2,3$ & $\begin{array}{l}\text { Número de emprendimientos } \\
\text { implementados a nivel cantonal }\end{array}$ & $\begin{array}{l}\text { GAD Municipales, GADs } \\
\text { Parroquiales,MAGAP, Comunidades } \\
\text { del cantón Alausí. }\end{array}$ & $\begin{array}{c}\text { GADs Provincial, Cantonal y } \\
\text { Parroquial. }\end{array}$ \\
\hline
\end{tabular}

Elaborado por: Angela Paulina Rivera Riera 
Tabla 5. Programas y Proyectos propuestos para el eje turístico

\begin{tabular}{|c|c|c|c|c|c|c|c|}
\hline $\begin{array}{l}\text { PRO } \\
\text { G. }\end{array}$ & PROYECTO & OBJETIVO & \begin{tabular}{|c|}
$\begin{array}{c}\text { PRESUPUESTO } \\
\text { USD }\end{array}$ \\
\end{tabular} & $\begin{array}{c}\text { AÑO DE } \\
\text { EJECUCION }\end{array}$ & INDICADOR DE GESTION & ACTORES INVOLUCRADOS & $\begin{array}{c}\text { FUENTES DE } \\
\text { FINANCIAMIENTO } \\
\end{array}$ \\
\hline \multirow{9}{*}{ 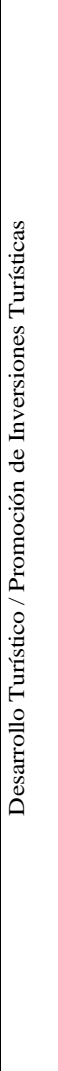 } & $\begin{array}{l}\text { Campañas de promoción y difusión turística } \\
\text { dentro del cantón }\end{array}$ & $\begin{array}{l}\text { Difundir a la población en general los } \\
\text { diversos atractivos turísticos } \\
\text { presentes en el cantón Alausí }\end{array}$ & $250.000,00$ & $1,2,3,4,5$ & $\begin{array}{l}\text { Número de campañas de difusión } \\
\text { realizadas }\end{array}$ & $\begin{array}{l}\text { Ministerio de Turismo,GAD Municipal, } \\
\text { GADs Parroquiales, Comunidades del } \\
\text { cantón Alausí. }\end{array}$ & $\begin{array}{c}\text { GADs Provincial, Cantonal y } \\
\text { Parroquial, Ministerio de } \\
\text { Turismo } \\
\end{array}$ \\
\hline & $\begin{array}{l}\text { Implementación de centros de interpretación } \\
\text { turistica dentro del cantón ( Tixán y } \\
\text { Achupallas) }\end{array}$ & $\begin{array}{l}\text { Promocionar paquetes turísticos } \\
\text { cantonales }\end{array}$ & $150.000,00$ & 2,4 & $\begin{array}{l}\text { Número de centros } \\
\text { implementados }\end{array}$ & $\begin{array}{l}\text { Ministerio de Turismo,GAD Municipal, } \\
\text { GADs Parroquiales, Comunidades del } \\
\text { cantón Alausí. }\end{array}$ & $\begin{array}{c}\text { GADs Provincial, Cantonal y } \\
\text { Parroquial, Ministerio de } \\
\text { Turismo } \\
\end{array}$ \\
\hline & $\begin{array}{l}\text { Señaletica turística dentro del cantón ( } \\
\text { Achupallas, Sevilla, Huigra) }\end{array}$ & $\begin{array}{l}\text { Facilitar el acceso de lapoblación a } \\
\text { los iconos turisticos cantonales }\end{array}$ & $90.000,00$ & 1,3 & $\begin{array}{l}\text { Número de atractivos que cuentan } \\
\text { con señaletica turística }\end{array}$ & $\begin{array}{l}\text { Ministerio de Turismo,GAD Municipal, } \\
\text { GADs Parroquiales, Comunidades del } \\
\text { cantón Alausí. }\end{array}$ & $\begin{array}{c}\text { GADs Provincial, Cantonal y } \\
\text { Parroquial, Ministerio de } \\
\text { Turismo } \\
\end{array}$ \\
\hline & $\begin{array}{l}\text { Talleres de capacitación a productores } \\
\text { artesanales con fines turísticos ( Comunidad } \\
\text { de Nizag) }\end{array}$ & $\begin{array}{l}\text { Fortalecer la produción de artesanías } \\
\text { dentro del cantón }\end{array}$ & $20.000,00$ & 1 & Número de talleres realizados & $\begin{array}{l}\text { Ministerio de Turismo,GAD Municipal, } \\
\text { GADs Parroquiales, Comunidades del } \\
\text { cantón Alausí. }\end{array}$ & $\begin{array}{c}\text { GADs Provincial, Cantonal y } \\
\text { Parroquial, Ministerio de } \\
\text { Turismo } \\
\end{array}$ \\
\hline & $\begin{array}{l}\text { Estudio e implementación de un Museo } \\
\text { Arqueologico en la parroquia Guasuntos. }\end{array}$ & $\begin{array}{l}\text { Conservar los hallasgos } \\
\text { arqueologicos existentes en el sector }\end{array}$ & $60.000,00$ & 2 & Número de manzanas pintadas & $\begin{array}{l}\text { Ministerio de Turismo,GAD Municipal, } \\
\text { GADs Parroquiales, Comunidades del } \\
\text { cantón Alausí, Ministrio de Patrimonio y } \\
\text { Cultura }\end{array}$ & $\begin{array}{c}\text { GADs Provincial, Cantonal y } \\
\text { Parroquial, Ministerio de } \\
\text { Turismo } \\
\end{array}$ \\
\hline & $\begin{array}{l}\text { Fortalecimiento del turismo comunitario } \\
\text { (Achupallas, La Matriz, Huigra, Tixán y } \\
\text { Multitud) }\end{array}$ & $\begin{array}{l}\text { Fortalecer procesos turisticos dentro } \\
\text { de la parroquias }\end{array}$ & $120.000,00$ & 2 & $\begin{array}{l}\text { Número de infraestructuras } \\
\text { turisticas implementadas }\end{array}$ & $\begin{array}{l}\text { Ministerio de Turismo,GAD Municipal, } \\
\text { GADs Parroquiales, Comunidades del } \\
\text { cantón Alausí, }\end{array}$ & $\begin{array}{c}\text { GADs Provincial, Cantonal y } \\
\text { Parroquial, Ministerio de } \\
\text { Turismo } \\
\end{array}$ \\
\hline & $\begin{array}{l}\text { Rehabilitación de Museo Arqueologico en la } \\
\text { parroquia Achupallas }\end{array}$ & $\begin{array}{l}\text { Conservar la historia que caracteriza } \\
\text { a la parroquia }\end{array}$ & $100.000,00$ & 3 & Museo Implementado & $\begin{array}{l}\text { Ministerio de Turismo,GAD Municipal, } \\
\text { GADs Parroquiales, Comunidades del } \\
\text { cantón Alausí. }\end{array}$ & \begin{tabular}{|c} 
GADs Provincial, Cantonal y \\
Parroquial, Ministerio de \\
Turismo \\
\end{tabular} \\
\hline & $\begin{array}{l}\text { Estudio e implementación de un paradero } \\
\text { turistico (Ozogoche) }\end{array}$ & Fortalecer procesos turisticos & $200.000,00$ & 2,3 & Paradero Implementado & $\begin{array}{l}\text { Ministerio de Turismo,GAD Municipal, } \\
\text { GADs Parroquiales, Comunidades del } \\
\text { cantón Alausí. }\end{array}$ & $\begin{array}{c}\text { GADs Provincial, Cantonal y } \\
\text { Parroquial, Ministerio de } \\
\text { Turismo } \\
\end{array}$ \\
\hline & $\begin{array}{l}\text { Construcción de un paradero turístico en el } \\
\text { camino del Inca ( Achupallas) }\end{array}$ & Fortalecer procesos turísticos & $100.000,00$ & 3,4 & Paradero Implementado & $\begin{array}{l}\text { Ministerio de Turismo,GAD Municipal, } \\
\text { GADs Parroquiales, Comunidades del } \\
\text { cantón Alausí. }\end{array}$ & $\begin{array}{c}\text { GADs Provincial, Cantonal y } \\
\text { Parroquial, Ministerio de } \\
\text { Turismo } \\
\end{array}$ \\
\hline
\end{tabular}

Elaborado por: Ángela Paulina Rivera Riera. 


\section{CONCLUSION}

En base a la información general del territorio se determina que el cantón Alausí tiene un potencial productivo y turístico considerable gracias a su privilegiada ubicación, riqueza de suelos y diversidad de pisos climáticos, así como la historia del transporte férreo que históricamente ha movido el intercambio de productos y actualmente intenta revivir la promoción turística a nivel internacional. Lo que se evidencia es la falta de un modelo de gestión efectivo que planifique el uso sostenible de recursos y la generación de políticas públicas eficaces construidas en base a la participación comunitaria de la población.

El acceso a la tecnología dentro del cantón todavía sigue siendo limitada se evidencia que la agricultura en el cantón requiere de una serie de mejoras así como también restricciones, para hacer eficiente el uso sustentable del suelo y lograr rentabilidad en la producción ya que la falta de rotación de cultivos viene causando el agotamiento descontrolado de los terrenos cuya vocación es eminentemente agrícola, situación que conlleva a una mayor dependencia en el uso de agroquímicos para obtener las cosechas deseadas, además de no poseer industrias que generen valor agregado a los productos.

Si bien el turismo es un potencial dentro del cantón, este todavía no logra posicionarse en el mercado nacional debido a la falta de promoción y difusión constante de los atractivos existentes.

Se evidencia la total ausencia de programas de capacitación que permita al productor adquirir los conocimientos necesarios para ampliar y desarrollar acciones eficientes logrando el mejoramiento de los factores productivos, situación que se deriva de la débil organización existente en la población.

La presente propuesta de desarrollo será un instrumento de planificación estratégica para del Gobierno Municipal en donde se identifica claramente las limitaciones y potencialidades del territorio respecto al sector económico productivo, para finalmente presentar una serie de programas y proyectos que permitirán lograr el desarrollo sostenible de la población en un periodo determinado de tiempo.

\section{References:}

1. ALBURQUERQUE F. (2002). Guia para agentes de Desarrollo Economico Territorial. Sevilla: Instituto de Desarrollo Regional.

2. ANDRADE, C. (2016). http://app.sni.gob.ec/snilink/sin/PORTAL_SNI/data_sigad_plus/sigadplusdiagnistico/046002 1480001_DIAGNOSTICO_30-10-2015-20-15-41.pdf 
3. BARTRA, A. (2007-2015). Definicionabc.com. Recuperado el 12 de Marzo de 2015, de Desarrollo Humano Sostenible: www.definicionabc.com/medio-ambiente/desarrollo-sostenible.php

4. ARMIJO, M. (2009). www.cepal.org. Recuperado el 20 de Noviembre de 2015, de Manual de Planificacón Estrategica e indicadores de desempeño del sector publico: http://www.cepal.org/ilpes/noticias/paginas/3/38453/manual_planific acion_estrategica.pdf

5. BARREIRO, D. (2000). Desarollo Sostenible. Recuperado el 5 de marzo de 2015, de Desarrollo desde el territorio: www.redel.cl/documentosbarreiroindex/html

6. BERMEO, A. (2015). Recuperado el 18 de 11 de 2015, de http://www.unep.org/gc/gc23/documents/ecuador-desarrollo.pdf

7. CHERVEL. (1991). Manual de evaluación economica de proyectos. El método de los efectos. Bogotá: Santillana S.A.

8. Constitución de la Repúplica del Ecuador. 2008.

9. COOTAD. (2010). Ecuador.

10. CORAGGIO. (2006). Desarrollo Local y Municipios Productivos.Cuarta Jornada del foro municipal de salud. Municipalidad de Vicente Lopez/ Buenos Aires.

11. COTORRUELO MENTA R. (Enero de 2011). Desarrollo Local. Recuperado el Enero de 2015, de Desarrollo Local: www10.iadb.org/intal/intalcdi/PE/2011/09398.pdf

12. Democracia y Cultura. Modelo Cultural. Bartra, R. 2000. CONVIVIO. Editorial Vuelta. México.

13. Departamento de asuntos económicos y sociales. División de Desarrollo Sostenible. ONU. Programa 21. Capítulo III, 2006:2

14. Economías de Escala. Proyecto académico de la Facultad de Economía. PUCE. 2016. Ecuador.

15. GADMCA. (2010). Diagnóstico del Cantón Alausí. Alausi.

16. GALLICCHIO. (2006). El desarrollo local: como conbinar gobernabilidad, desarrollo economico y capital social en el territorio. Argentina: Publicaciones S.A.

17. GALLICCHIO. (2010). El desarrollo local: ¿territorializar políticas o generar políticas territoriales? Reflexiones desde la práctica. EUTOPIA.

18. INEC, 2016: 3. Ecuador.

19. KOERNOEV. (2001). Strategic environmental assessment and the decisión-making process. New York: Devuyst,D ed. 
20. MORENO, B. (2005). Eloy Alfaro creador del estado moderno y libertador de la mujer.

21. http://bayardomorenopiedrahitatates.blogspot.com/2005/11/eloyalfaro-creador-del-estado-moderno.html.

22. OJEDA, A. (2000). La descentralizacion en el Ecuador. Avatares de un proceso inconcluso. Abya-Yala. pp. 20

23. PLAN DE DESARROLLO DE CUENCA. (2011). WWW.CUENCA.GOB.EC.

24. PLAN NACIONAL DE DESARROLLO, 2. $\quad$-2. (2013). SENPLADES.

25. RAMÓN, G. (2004). El desarrollo local en el Ecuador: Historia, Actores y Métodos. Abya-Yala. pp. 15. 